\title{
Diagnosis of Mobile Robots Drives
}

\author{
Yu. Nikitin, A. Abramov, I. Abramov, \\ A. Romanov, S. Trefilov, Yu. Turygin \\ Department of Mechatronic Systems, \\ Kalashnikov Izhevsk State Technical University, \\ Izhevsk, Russian Federation \\ E-mail: ms@istu.ru
}

Received: June 12, 2018

\begin{abstract}
The imitation model of the mobile robot drive for diagnostics is considered. The drive is based on brushless direct current (BLDC) motor. The model was developed using the SimInTech software. Classification of signals of the mobile robot drive is performed: control signals, diagnostic signals and mixed signals. Mechanical and electrical defects in the drive are analyzed. The diagnostic parameters of the mobile robot drive are chosen: electric current, temperature and vibration. The reasons causing these defects of mobile robot drive are considered. A logical-linguistic diagnostic model of drive has been developed on basis of fuzzy logic. The calculated rules determine dependence of technical condition on diagnostic parameters, their trends and utilized lifetime of mobile robot drive. Experimental results of mobile robot drive diagnostics are discussed. It is shown that in the process of degradation, the change in the state of the drive affects the diagnostic parameters.
\end{abstract}

Keywords: diagnostics, mobile robot, drive, brushless DC motor, model, fuzzy logic.

\section{INTRODUCTION}

Mobile robots work in extreme conditions. To increase the robustness of mobile robots, their diagnosis is required. Most often, the drives fail. Therefore, the paper is devoted to the diagnosis of drives of mobile robots. In modern drives of mobile robots, brushless direct current (BLDC) motors are used as electric motors.

BLDC motors are a type of electric motors that rapidly gains popularity due to its good performance and the development of microprocessor controls. In [1-2] the diagnosis of electric motors using the signals of electric current and resistance is considered. New PWM switching strategy to minimize the torque ripples in BLDC motor which is based on sensored rotor position control is discussed in the paper [3]. Tuning methodology for the parameters of adaptive current and speed controllers in a permanent-magnet BLDC motor drive system is presented in paper [4]. Two Fault Detection and Diagnosis strategies for detecting BLDC motor faults were considered involving wavelets and state estimation [5]. Bearing faults and stator winding faults, which are responsible for the majority of motor failures, are considered [5]. A novel method using windowed Fourier ridges is proposed in paper [6] for the detection of rotor faults in BLDC motors operating under continuous non-stationarity. The use of quadrat-

(C) Nikitin Yu., Abramov A., Abramov I., Romanov A., Trefilov S., Turygin Yu., 2018 
ic TFRs is presented as a solution for the diagnostics of rotor faults in BLDC motors operating under constantly changing load and speed conditions [7]. Four time-frequency representations are considered short-time Fourier transform (STFT), Wigner-Ville distribution (WVD), Choi-Williams distribution (CWD), and the Zhao-Atlas marks distribution (ZAM) [7]. Three new algorithms for the detection BLDC motors faults are proposed that can track and detect rotor faults in non-stationary or transient current signals [8]. Park's vector method was used to extract the features and to isolate the BLDC motors faults from the current measured by sensors [9]. Proposed a model of a fault diagnosis expert system with high reliability to compare identical well-functioning BLDC motors [10]. The application of artificial intelligence for the control and diagnostics of electric motors was considered in [11-14]. In [11-13] fuzzy fault detection and diagnosis of electric motors with is considered. During the past several decades, the design of model-based process monitoring systems has been a remarkable research topic. In contrast, the data-driven process monitoring techniques serve as an efficient alternative way, which have gained lots of attention from both the academic and the industrial field. A straightforward way is to utilize the process history data for model identification and based on it, the well-established model-based techniques can be used to design efficient fault diagnosis system. For this purpose, Subspace Identification Method that directly identifies the complete state-space matrices has gained more attention in the last two decades and has been successfully implemented in many industrial applications [14]. To improve the reliability of detection of mobile robot drive defects, it is suggested to use the electric current, vibration and temperature signals and the fuzzy logic.

\section{INTEGRATION OF THE MOBILE RoBOt DRIVE CONTROL AND DiAGNOSTIC SYSTEMS}

The authors propose to integrate the mobile robot drive control and diagnostic systems. The economic efficiency of diagnostic systems is due to increase in reliability and quality, accident risk and reject rate reduction, decrease of expensive equipment downtime, reduction of maintenance and repair costs and increase of service life.

Classification of signals of the mobile robot drive is performed: control signals, diagnostic signals and mixed signals. Control signals include: signals from sensors that determine the speed of rotation, the angle of rotation of the shaft. Diagnostic signals include vibration, temperature signals. Mixed signals include those signals that are used for both control and diagnosis - electrical current. For correct diagnosis, it is also necessary to take into account the parameters that determine the mode of operation: the weight of the load, the angle of inclination of the surface along which the robot moves, and the quality of the surface.

To investigate BLDC control, a simulation model of BLDC motor in natural (phase) coordinates has been created using SimInTech software (Fig. 1).

Simulation model of BLDC control allows to determine the relationships for phase currents and back electromotive force of perfect BLDC which can be used as diagnostic parameters. To improve diagnostics accuracy, the analysis of faults and other BLDC diagnostic parameters is required.

For the purpose of BLDC diagnostics the BLDC faults have been grouped into two classes - of electrical and mechanical faults. BLDC motor faults are shown in Table 1.

Selected diagnostic parameters (electric current, vibration and temperature) are shown in Table 2.

Processing of diagnostic parameter measurements is required to make decision regarding the mobile robot drive technical condition. Fuzzy logic is the most suitable mathematical tool for diagnostic model construction. 


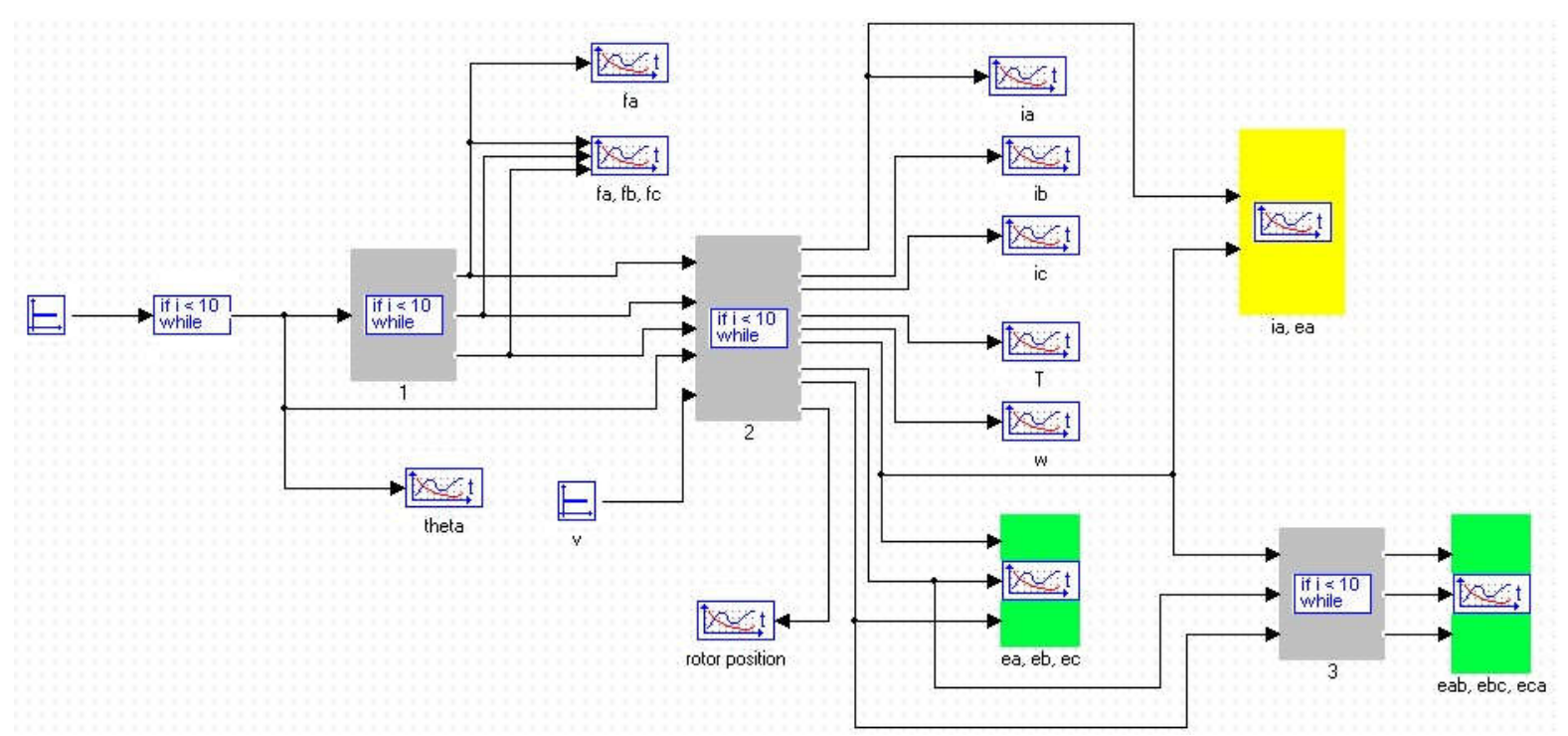

Figure 1. Simulation model of BLDC motor

Table 1. Drive faults

\begin{tabular}{l|l}
\hline \multicolumn{1}{c|}{ Electrical faults } & \multicolumn{1}{c}{ Mechanical faults } \\
\hline $\begin{array}{l}\text { conductor break in the winding; } \\
\text { short circuit between the winding turns; }\end{array}$ & $\begin{array}{l}\text { degradation processes in the bearings - } \\
\text { unacceptable reduction of the insulation resistance }\end{array}$ \\
$\begin{array}{l}\text { due to insulation ageing or excessive moisture; } \\
\text { poor contacts and connections }\end{array}$ & $\begin{array}{l}\text { poor heat transfer due to foul or dusty coils; } \\
\text { rotor shaft deformation }\end{array}$ \\
\hline
\end{tabular}

Table 2. Drive diagnostic parameters

\begin{tabular}{l|l}
\hline \multicolumn{1}{c|}{ Diagnostic parameter } & \multicolumn{1}{c}{ Cause of diagnostic parameter change } \\
\hline Electric current & overload; winding break or short circuit; mains voltage change \\
\hline Temperature & overload; winding short circuit; ambient temperature change \\
\hline Vibration & shaft misalignment; bearing faults \\
\hline
\end{tabular}

\section{Logical-Linguistic Diagnostic Model of Drive}

Logical-linguistic drive diagnostic model based on fuzzy logic may be represented by the following system of equations:

$$
\left\{\begin{array}{l}
x(t)=F\left(x_{1}(t), x_{2}(t), x_{3}(t)\right) \\
D(t)=G(x(t), t) \\
Z(t)=H(x(t), D(t), t)
\end{array}\right.
$$

where $x(t)=F\left(x_{1}(t), x_{2}(t), x_{3}(t)\right)$ - equation of diagnostic parameters; $x(t)-$ vector of diagnostic parameters; $x_{1}(t), x_{2}(t), x_{3}(t)$ - a set of diagnostic parameter measurements; $D(t)=G(x(t), t)$ - equation to calculate the trend vector of diagnostic parameters; $t$ - utilized lifetime; $Z(t)=H(x(t), D(t), t)$ - equation to evaluate the technical condition. 
The model of diagnostic system (Fig. 2) is based on the mathematical apparatus of fuzzy logic. The model allows to determine the mobile robot drive condition from diagnostic parameters (electric current, vibration and temperature). The simulation model of mobile robot drive diagnostics system has been designed in SimInTech software.

Fig. 2 shows the simulation model of the diagnostic system used for assessment of mobile robot drive condition.

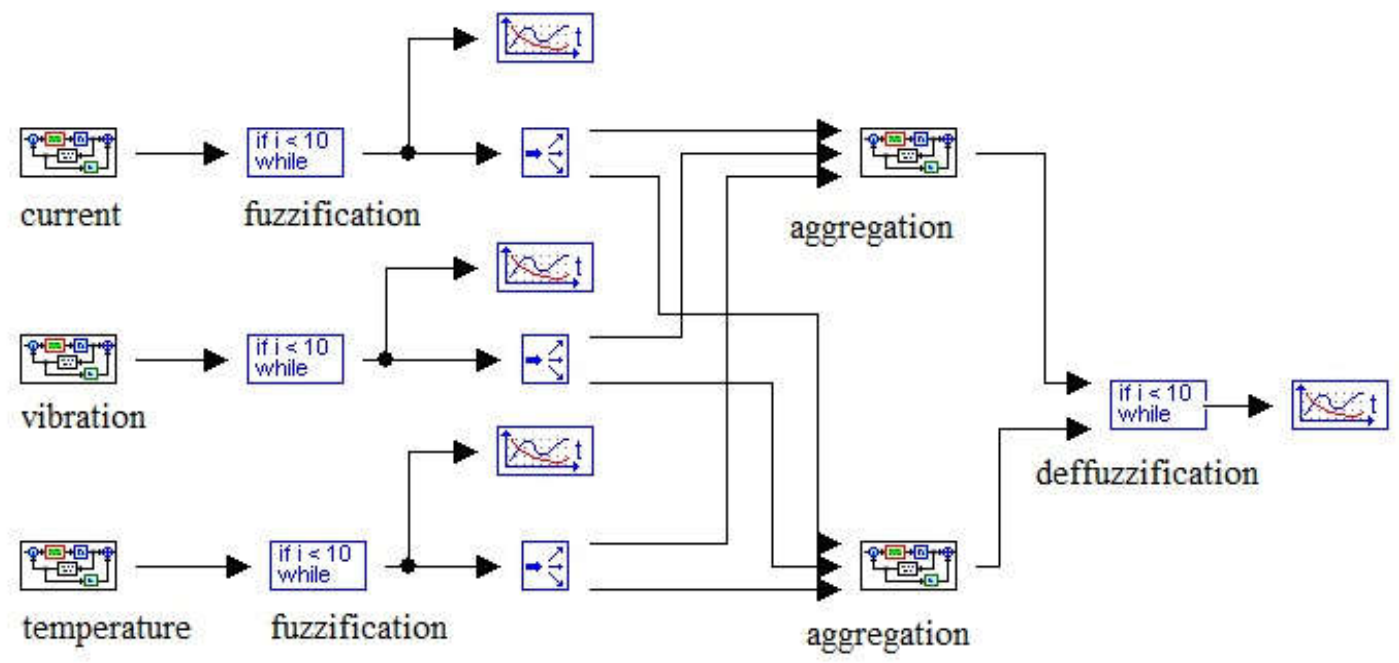

Figure 2. Simulation model of mobile robot drive of the diagnostic system

Fig. 3 shows simulation results of the temporal changes (in relative units) of input signals (electric current (1), vibration (2) and temperature (3)) caused by mobile robot drive fault. Behavior of the output variable, characterizing the degree of drive defect growth, is shown in Fig. 4.

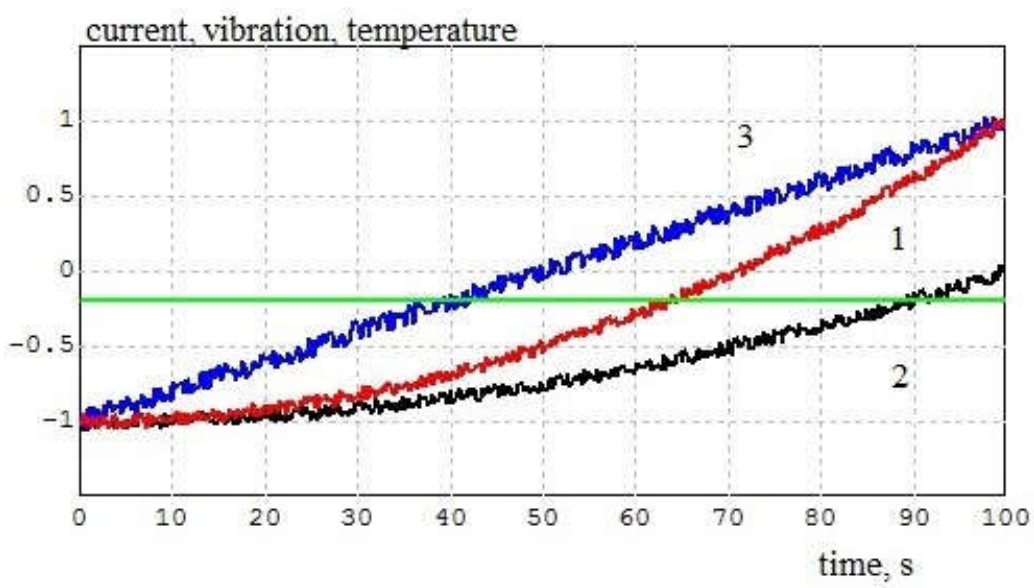

Figure 3. Simulation results of the temporal changes of input signals (electric current, vibration and temperature) caused by drive fault (in relative units)

\section{DISCUSSION}

The resulting curve implies that on the interval $0 \ldots 20 \mathrm{~s}$ drive is in operational condition. Development of drive degradation processes occurs on the interval $30 \ldots 80 \mathrm{~s}$. On the interval $90 \ldots 100 \mathrm{~s}$ drive is in alarm condition. Dynamics of degradation processes can be judged by 
the nature of the curve: change of the drive condition from operational to alarm does not happen immediately; it takes place with the increase of diagnostic parameters.

In this way, by analyzing drive diagnostic parameters, trend and operating time we can foresee the emergency situation, minimize accident risk and timely schedule the drive maintenance and repair works. Experiments were carried out with diagnostic parameters being within and beyond the tolerable limits. The both experiments were performed at the same supply voltage and load torque. The simulation model of drive control and diagnostic system may be used to study the influence of diagnostic parameters on drive performance.

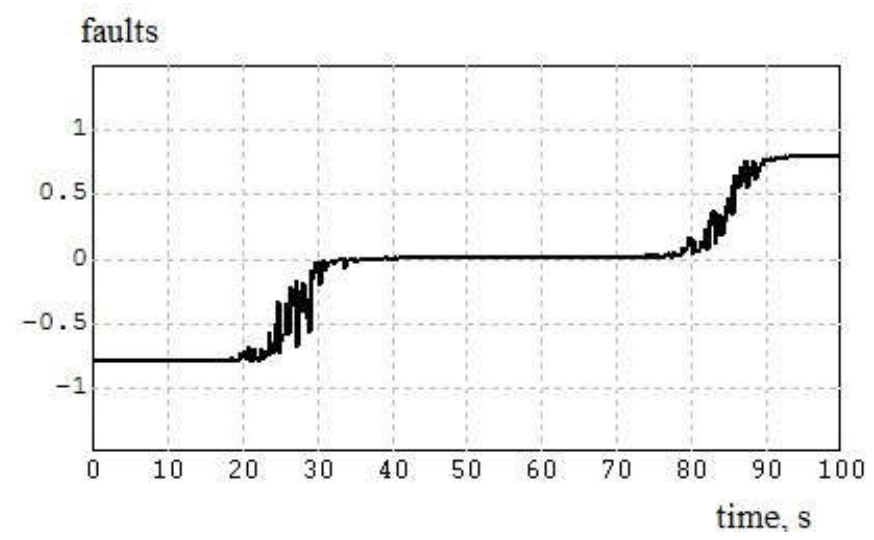

Figure 4. Condition of drive in the course of degradation depending on diagnostic parameters

\section{CONCLUSIONS}

It follows from the paper that a simulation model of diagnostic system built using MiTD software can be efficiently used for drive diagnostics. The model is based on mathematical apparatus of fuzzy logic. It allows to determine the drive condition from diagnostic parameters (electric current, vibration and temperature).

Trend of the integral parameter allows to calculate the expected time point when the limit technical condition will be reached and to minimize the risk of premature failure through accident-preventive measures like scheduling of routine maintenance and repair. In case of development of drive degradation processes during the operation one can change the control action on the drive by reduction in electric current and so switch over to derated operation mode.

The simulation experiments confirmed the efficiency of the proposed diagnostic model and the prospects of its application to diagnostics of mobile robot drive. Application of together electric current, vibration and temperature signals allows to detect defects of mobile robot drive. It is expected that using the fuzzy logic method will further increase the reliability of detecting defects in the mobile robot drive.

\section{ACKNOWLEDGMENT}

The reported study was funded by RFBR according to the research project No. 18-08-00772 A.

\section{REFERENCES}

1. Seera, M., Lim, C. P., Ishak, D., \& Singh, H. (2012). Fault detection and diagnosis of induction motors using motor current signature analysis and a hybrid FMM-CART model. IEEE Transactions on Neural Networks and Learning Systems, 23(1), 97-108. doi: 10.1109/TNNLS.2011.2178443. 
2. Cheng, S., Zhang, P., \& Habetler, T. G. (2011). An impedance identification approach to sensitive detection and location of stator turn-to-turn faults in a closed-loop multiple-motor drive. IEEE Transactions on Industrial Electronics, 58(5), 1545-1554. doi: 10.1109/TIE.2010.2064276.

3. Wael, A. S., Dahaman, I., \& Khaleel, J. H. (2011). PWM switching strategy for torque ripple minimization in BLDC motor. Journal of Electrical Engineering, 62(3), 141-146. doi: 10.2478/v10187-011-0023-1.

4. Mohamed, A. A., Ehab, H. E. B., \& Hisham, M. S. (2009). Adaptive deadbeat controllers for brushless DC drives using PSO and ANFIS techniques. Journal of Electrical Engineering, 60(1), 3-11.

5. Zhang, W. (2013). A fault detection and diagnosis strategy for permanent magnet brushless DC motor (Masters thesis, McMaster University, Hamilton, Ontario, Canada). Retrieved from https://macsphere.mcmaster. ca/bitstream/11375/12737/1/fulltext.pdf.

6. Rajagopalan, S., Habetler, T. G., Harley, R. G., Aller, J. M., \& Restrepo, J. A. (2005). Diagnosis of rotor faults in brushless DC (BLDC) motors operating under non-stationary conditions using windowed Fourier ridges. In: Fourtieth IAS Annual Meeting. Conference Record of the 2005 Industry Applications Conference, 1 (pp. 26-33). Kowloon, Hong Kong, China : IEEE. doi: 10.1109/IAS.2005.1518287.

7. Rajagopalan, S., Restrepo, J. A., Aller, J. M., Habetler, T. G., \& Harley, R. G. (2005). Selecting timefrequency representations for detecting rotor faults in BLDC motors operating under rapidly varying operating conditions. In: 31st Annual Conference of IEEE Industrial Electronics Society, 2005. IECON 2005 (pp. 1-6). Raleigh, NC, USA : IEEE. doi: 10.1109/IECON.2005.1569314.

8. Rajagopalan, S. (2006). Detection of rotor and load faults in brushless DC motors operating under stationary and non-stationary conditions (Doctoral thesis, Georgia Institute of Technology, USA). Retrieved from https://smartech.gatech.edu/handle/1853/11524? show=full.

9. Bae, H., Kim, S., \& Vachtsevanos, G. (2009). Fault detection and diagnosis of winding short in BLDC motors based on fuzzy similarity. International Journal of Fuzzy Logic and Intelligent Systems, 9(2), 99-104. doi: 10.5391/IJFIS.2009.9.2.099.

10. Baek, G., Kim, Y., \& Kim, S. (2008). Fault diagnosis of identical brushless DC motors under patterns of state change. In: 2008 IEEE International Conference on Fuzzy Systems (IEEE World Congress on Computational Intelligence) (pp. 2083-2088). Hong Kong, China : IEEE. doi: 10.1109/FUZZY.2008.4630657.

11. Abramov, I., Abramov, A., Nikitin, Yu., Sosnovich, E., Božek, P., \& Stollmann, V. (2015). Diagnostics of electrical drives. In: 2015 International Conference on Electrical Drives and Power Electronics (EDPE) (pp. 364-367). Tatranska Lomnica, Slovakia : IEEE. doi: 10.1109/EDPE.2015.7325321.

12. Abramov, I., Božek, P., Abramov, A., Sosnovich, E., \& Nikitin, Y. (2017). Diagnostics brushless DC motors. In: F. Trebuňa, J. Bocko, P. Frankovský, R. Huňady, J. Kostka, T. Kula (Eds.), 55th International Conference on Experimental Stress Analysis (EAN 2017) (pp. 156-164). Novy Smokovec, Slovakia : Curran Associates. Retrieved from http://experimentalni-mechanika.cz/konference/2017.html?download=1363: diagnostics-brushless-dc-motors.

13. Costa, B. S. J. (2016) Fuzzy fault detection and diagnosis. In: P. P. Angelov (Ed.), Handbook on computational intelligence: Vol. 1. Fuzzy logic, systems, artifical neural networks, and learning systems (pp. 251-288). Singapore : World Scientific. doi: 10.1142/9789814675017_0007.

14. Luo, H. (2017). Plug-and-play monitoring and performance optimization for industrial automation processes. Wiesbaden, Germany : Springer Vieweg. doi: 10.1007/978-3-658-15928-3. 